\title{
A demographic study of a series of eosinophilic appendicitis and its correlation with the clinicopathological profile in a tertiary care hospital-a 3-year study
}

\author{
Padmavathy K. ${ }^{1 *}$, Arumugam VG. ${ }^{2}$, Illavarasan E. ${ }^{3}$, Srinivasan . $^{4}$ \\ DOI: https://doi.org/10.17511/jopm.2020.i02.08 \\ 1* Karthika Padmavathy, Department of Pathology, Sri Muthukumaran Medical College and RI, Chennai, Tamil Nadu, India. \\ ${ }^{4}$ Vijayalakshmi Srinivasan, Department of Pathology, Sri Muthukumaran Medical College and RI, Chennai, Tamil Nadu, India.
}

2 Vasugi Gramani Arumugam, Department of Pathology, SRIHER, Chennai, Tamil Nadu, India.

3 Elakkiya Illavarasan, Consultant, Humain Health Clinic and Lab, Chennai, Tamil Nadu, India.

Introduction: Acute eosinophilic appendicitis ( $A E A$ ) is a rare variant of inflammation of the appendix. The histologic hallmark of this entity is the infiltration of eosinophils in the musularis layer of the appendix with edema separating the muscle fibers with very few or no neutrophilic infiltration. A retrospective study was done to determine their demographic profile, morphological diagnosis, and clinical correlation. Materials and Methods: All cases of Acute appendicitis reported at the histopathology department of Sri Muthukumaran Medical College and Research Institute, a teaching hospital from the year of Jan 2017 to Dec 2019 were included in this study. Histopathological examination is the gold standard for the diagnosis of acute appendicitis. Hence, Formalin-fixed paraffin-embedded tissue which was stained with Hematoxylin and Eosin were retrieved and used for routine morphology and diagnosis. Results: Out of 419 cases of appendicectomies studied, 27 $(6.49 \%)$ cases were found to be acute eosinophilic appendicitis, $265(63.7 \%)$ cases were acute appendicitis, $30(7.2 \%)$ cases were reported as acute suppurative appendicitis with periappendicitis most of which showed infiltration of eosinophils along with other inflammatory cells and 97 (23.3\%) cases were reported as appendix with reactive lymphoid hyperplasia. Conclusion: It was inferred that the acute eosinophilic appendicitis is a condition which could be an allergic response and an early event in the evolution of acute phlegmonous appendicitis.

Keywords: Appendicitis, Eosinophilic, Allergic response

Corresponding Author

Karthika Padmavathy, Department of Pathology, Sri Muthukumaran Medical College and RI, Chennai, Tamil Nadu, India.

Email: karthikaprem@hotmail.com
How to Cite this Article

Padmavathy K, Arumugam VG, Illavarasan E, Srinivasan V. A demographic study of a series of eosinophilic appendicitis and its correlation with the clinicopathological profile in a tertiary care hospital-a 3-year study. Trop J Pathol Microbiol. 2020;6(2):161-166.

Available From

https://pathology.medresearch.in/index.php/jopm/ar

ticle/view/424
To Browse

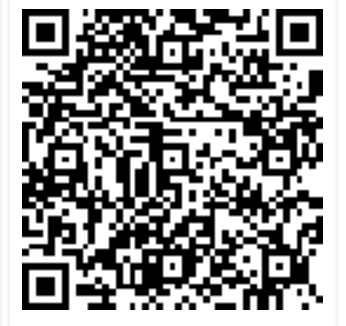

Manuscript Received 20-01-2020

Conflict of Interest No
Review Round 1 30-01-2020

Funding

$\mathrm{Nil}$

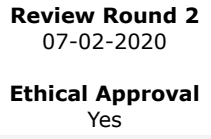

Ethical Approval Yes

Review Round 3

Plagiarism X-checker $19 \%$
Accepted 11-02-2020

(c) 2020 by Karthika Padmavathy, Vasugi Gramani Arumugam, Elakkiya Illavarasan, Vijayalakshmi Srinivasan and Published by Siddharth Health Research and Social Welfare Society. This is an Open Access article licensed under a Creative Commons Attribution 4.0 International License https://creativecommons.org/licenses/by/4.0/ unported [CC BY 4.0]. 


\section{Introduction}

Acute eosinophilic appendicitis (AEA) is a rare clinical entity that is characterized clinically by acute abdominal pain and a grossly inflamed appendix with few or absence of neutrophils in the muscle layer microscopically.

The histologic hallmark of Acute eosinophilic appendicitis is eosinophilic infiltration of the muscularis propria with accompanying edema separating the muscle fibers.

The diagnosis of classic suppurative appendicitis (phlegmonous appendicitis) should be made only in the presence of neutrophils in the muscularis propria [1]. Some investigators have considered more than 10 neutrophils/5 HPF found in the mucosa to be evidence of early appendicitis [2].

On the other hand, Pieper et al [3] found inflammation limited to the mucosa in appendices removed incidentally and suggested that the condition is not responsible for actual complaints.

Acute eosinophilic appendicitis is not completely understood as there are no clear criteria defining the disease. There are very few studies with respect to the observation of eosinophilic infiltration of the muscularis propria in the absence of any other abnormality $[4,5]$.

Hence in the present study, an attempt was done to study the incidence of Acute eosinophilic appendicitis.

\section{Materials and Methods}

Place of the study: Department of Pathology, Sri Muthukumaran Medical College, Hospital and RI, Chikkarayapuram, Kundrathur Road, Near Maangadu, Chennai, Tamil Nadu, India

Duration: Jan 2017 to Dec 2019

Type of the study: Retrospective

Sampling Methods: A total of 419 cases were collected in our tertiary care hospital. After formalin fixation, they were sectioned and the sections were routinely processed and stained with hematoxylin and eosin. The criteria used in the diagnosis of AEA were transmural eosinophilic infiltrate in the appendix wall, more than 25 eosinophils per high power field in muscularis mucosa, absence of polymorphs or any other pathology in the wall [6].
Specimens presenting in our department over a period Jan 2017 to Dec 2019 were included in this study.

Exclusion criteria: Appendix present along with colectomy specimens were excluded from this study.

Ethical consideration and permission: The study was conducted as per Ethical guidelines for biomedical research on human participants and ICMR (Indian Council of Medical Research (2006)].

Statistical analysis: Statistical analysis was done by calculating number and percentage for computing the incidence in various age groups, in sexes, and also a comparison with other studies.

\section{Results}

A total of 419 cases were collected in our tertiary care hospital between Jan 2017 to Dec 2019. Out of 419 cases of appendicectomies studied, 27 cases were found to be acute eosinophilic appendicitis [Figure-1], 265 cases were acute appendicitis [Figure-2], 30 cases were reported as acute suppurative appendicitis with peri appendicitis [Figure-3] most of which showed eosinophils along with other inflammatory cells and 97 were reported as appendix with reactive lymphoid hyperplasia [Figure-4] [Chart 1].

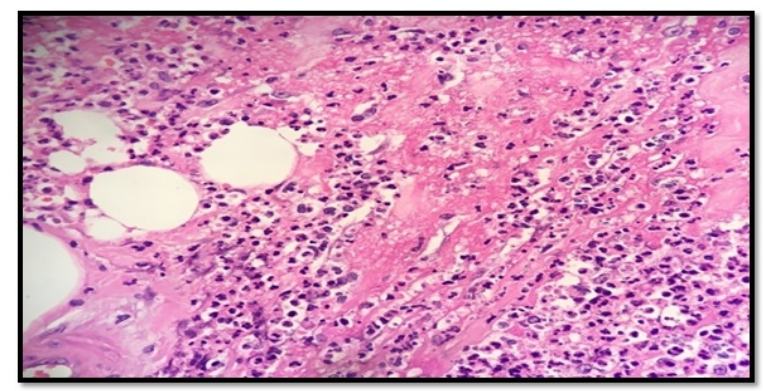

Fig-1: Acute Eosinophilic appendicitis $H$ and $E$ $x$ 400x.

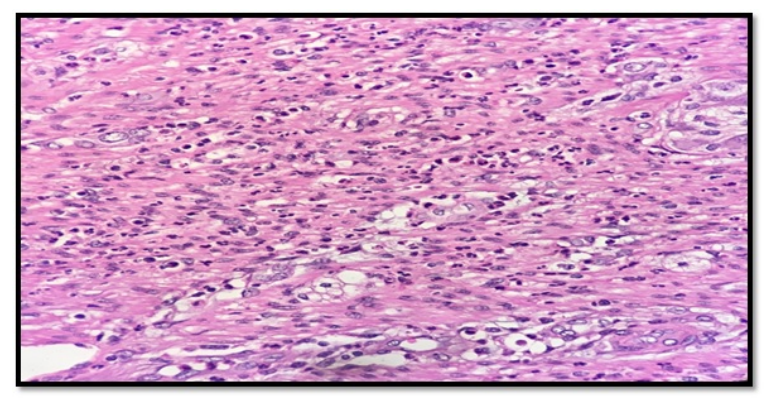

Fig-2: Acute appendicitis $H$ and E X 400x. 


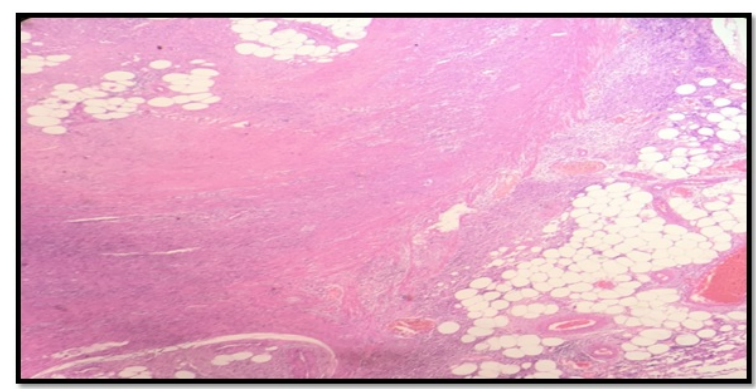

Fig-3. Acute suppurative appendicitis with periappendicitis $H$ and $E X$ 100x.

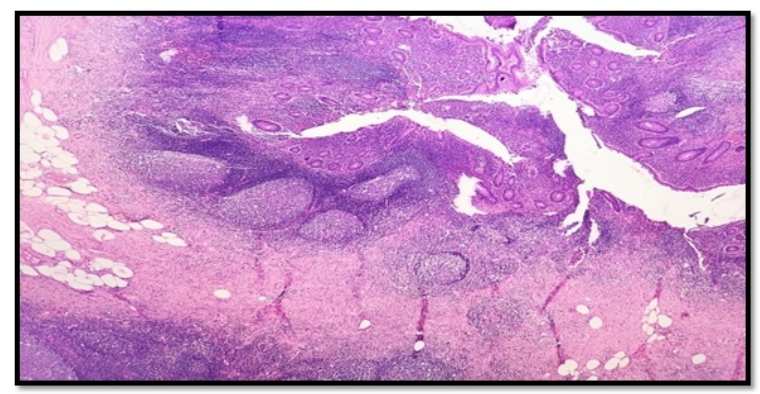

Fig-4: Appendix with reactive lymphoid hyperplasia $H$ and E X 200x.

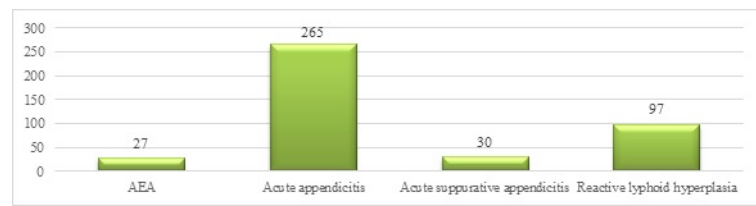

\section{Chart 1: Distribution of appendicectomy cases.}

Most of the acute appendicitis showed gross edema and congested blood vessels on the serosal surface. Enterobius vermicularis worm infestation was noted in 7 cases reported as acute eosinophilic appendicitis and in 20 cases of acute appendicitis [Chart 2].

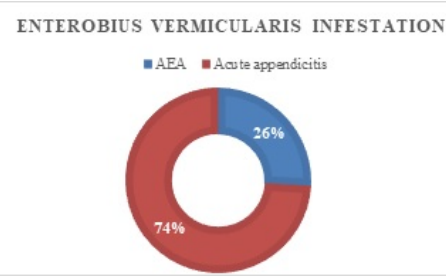

\section{Chart 2: Worm infestation in AEA and Acute appendicitis.}

$27(6.4 \%)$ out 419 appendectomy patients aged between 5 years to 60years showed AEA. The patients with AEA comprised 16 adult male $(60 \%)$, 6 Male children (20\%) and 5 females (20\%) with median age 26.8 years [Chart 3 ].

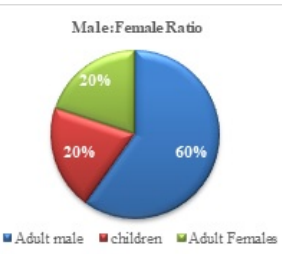

\section{Chart 3: Demographic profile}

In the current study, there was no $\mathrm{H} / \mathrm{O}$ allergy, no peripheral eosinophilia and there was no history of parasitic infestation. The chief complaint in all cases was pain abdomen while in a few cases nausea and vomiting were also present.

\section{Discussion}

Although the vermiform appendix is considered to be a vestigial organ, it has a propensity for acute inflammation leading to complications. Reginald Fitz first recognized acute appendicitis as a clinical entity. Later in the 1500s, Charles Mc Burney described the clinical manifestations of acute appendicitis.

The peak incidence of acute appendicitis is seen in the second decade of life. Based on symptoms, signs and diagnostic tests in patients presenting with right iliac fossa pain, acute appendicitis can be diagnosed using a scoring system called the Alvarado scoring system. A score of seven or more is strongly predictive of acute appendicitis (Alvarado, 1986) [13].

One of the important etiologies of acute appendicitis is luminal obstruction due to faecolith, fibrosis, or stricture. The luminal narrowing may also be due to lymphoid hyperplasia. Once luminal obstruction occurs, continued mucus secretion and inflammatory exudation lead to increased intraluminal pressure resulting in obstruction of lymphatic drainage.

Thereby, leading to intense edema, appendiceal gangrene and finally perforation. In a study by Shreshtha et al, fecoliths were found in $40 \%$ cases of acute appendicitis leading to gangrenous appendicitis with or without rupture in a majority of cases (Shreshtha et al., 2012) [14].

Bickell et al [15] have reported that the rate of appendicular perforation increases by $5 \%$ every 12 hours, after a period of 36 hours after the onset of symptoms (Bickell, 2006). This emphasizes the need for expedient diagnosis and treatment of this condition (Bhangu, 2015) [16]. 
The need for histopathological examination of all the appendectomy specimens has long been debated. However, in their study Sinha et al [17] have highlighted that histologically unusual pathologies may coexist in appendectomy specimens. Thus, justifying the need of histopathological examination of all appendectomy specimens.

Duzgun et al [18] found that histopathological examination of the appendectomy specimen may also disclose additional pathological findings that may not be evident on gross examination intraoperatively but may affect subsequent clinical management of the patient (Duzgun et al., 2004).

Traditionally, suppuration or neutrophilic infiltration has been the path gnomonic feature of acute appendicitis on histopathology (Liu et al., 2004) [19]. Eosinophilic gastroenteritis is a known entity, characterized by eosinophilic infiltration of one or more areas of the gastrointestinal tract extending from the esophagus to colon with the presence of gastrointestinal symptoms.

Although peripheral blood eosinophilia is not a universal finding in eosinophilic gastroenteritis, it occurs in 20-90\% of cases (Blackshaw et al., 1986 [20]). Stephenson et al described the presence of eosinophilic infiltrates in the muscle layer in appendicitis. They called this entity 'subacute appendicitis' [11].

Acute eosinophilic appendicitis was first proposed and defined by Aravindan et al [7] in 2010. They proposed that the development of acute appendicitis is triggered by type I hypersensitivity reaction and morphology is characterized by eosinophilicedematous lesion occurring in the appendix. Superadded bacterial infection leads to acute suppurative appendicitis with periappendicitis and abscess formation.

They noticed a fluctuation in blood eosinophil count which first increased and then decreased over time in cases of acute suppurative and eosinophilic appendicitis They also proposed that AEA should be evaluated as a variant of acute appendicitis rather than an extension of eosinophilic gastroenteritis. In early times, eosinophilic appendicitis was characterized by worm infestation, granulomas and associated tissue infiltration by eosinophils [8].

On the contrary, eosinophilia persists and does not resolve over time in eosinophilic gastroenteritis cases [9]. It was also observed that Enterobius vermicularis worm infestation in 7 cases reported as
Acute eosinophilic appendicitis, but no evidence was observed of granulomas in any of the current cases.

Gaurav Jain et al [6] reviewed 268 appendectomy cases, of which $5(1.9 \%)$ cases were found to have eosinophilic appendicitis. There was a male preponderance. In the current study 27 (6.4\%) out 419 appendectomies, patients aged between 5 years to 60years showed AEA. The patients with AEA comprised 16 adult males (60\%), 6 Male children (20\%) and 5 females (20\%) with a median age of 26.8 years. The present study also showed male preponderance.

Shivraj N Kanthikar et al [10] reported a primary eosinophilic appendicitis is a rare condition of unknown etiology having vague and unexplained symptoms. The histopathological hallmark of this entity is eosinophilic infiltration of the muscularis propria with accompanying edema separating the muscle fibers, and the absence of neutrophilic infiltration. The preoperative correct diagnosis of this entity is not possible in view of the lack of specific imaging technology. Histopathological examination is the gold standard for the diagnosis.

Some investigators [11] have considered these scattered eosinophils observed in muscularis propria as sub-acute appendicitis but without any evidence of clinical relevance [5]. It was believed that the term sub-acute appendicitis lacks clinical significance and leads to confusion. Hence, it should be avoided.

Carr NJ [5] proposed that an eosinophil count in excess of 10 per $\mathrm{cm}$ (25 per $10 \mathrm{HPF}$ ) could be labeled as eosinophilic appendicitis. Our cases also fulfilled the criteria. In our case, eosinophils were present in all the layers including muscularis propria (25-30per HPF).

Marc E. Rothenberg et al [12] done a study in which Primary eosinophilic gastrointestinal disorders are defined as disorders that selectively affect the gastrointestinal tract with eosinophil-rich inflammation in the absence of known causes for eosinophilia (eg, drug reactions, parasitic infections, and malignancy).

These disorders include eosinophilic esophagitis, eosinophilic gastritis, eosinophilic gastroenteritis, eosinophilic enteritis, and eosinophilic colitis and are occurring with increasing frequency. Significant progress has been made in elucidating that eosinophils are integral members of the gastrointestinal mucosal immune system and that 
Eosinophilic gastrointestinal disorders are primarily polygenic allergic disorders that involve mechanisms that fall between pure IgE-mediated and delayed TH2-type responses. The steroid is the mainstay of treatment of eosinophilic enteritis and sodium cromoglycate, ketotifen, montelukast may be tried.

Complicated case with obstruction and perforation requires surgical intervention. Otherwise, the surgeon should avoid unnecessary surgical intervention in case of eosinophilic enteritis.

In the case of parasitic infestation, it results in tissue injury and local irritation in the gastrointestinal tract and a cure is possible with medical therapy. Hence once eosinophilic appendicitis is being diagnosed, the patient should be completely evaluated for eosinophilic enteritis and parasitic infestations.

Limitation of the study: Follow up data could not be obtained from all the patients for the correlation study.

\section{Conclusion}

Primary acute eosinophilic appendicitis is a rare existing entity. If the appendix is found congested in patients undergoing laparotomy for other etiologies, these congested appendices should be removed. Adopting such therapeutic modality can prevent future occurrence of acute appendicitis and hence need for appendectomy later in life. It is important to conduct further studies about AEA, for better diagnostic approach and management, as well as understanding the pathogenesis of this entity.

\section{What does this study add to existing knowledge?}

- Acute eosinophilic appendicitis may simulate uncomplicated appendicitis

- AEA may on respond only to antibiotic therapy

- Careful follow up may be needed because of the risk of eosinophilic enteritis.

\section{Author's Contributions}

Dr. Karthika Padmavathy: Study concept, Data collection, Data analysis

Dr. Vasugi Gramani Arumugam: Data analysis, manuscript preparation

Dr. Elakkiya Illavarasan: Manuscript preparation
Dr. Vijayalakshmi Srinivasan: Study concept, study design

\section{Reference}

01. Liu C, Crawford JM. The Gastrointestinal tract, In; Kumar $V$, Abbas $A K$, Fausto $N$, eds. Philadelphia PA- Elsevier inc, Robbins and Cotran Pathologic Basis of Disease, 7th edition. 2004, p;797-875.

[Crossref]

02. Barcia JJ, Reissenweber N. Neutrophil count in the normal appendix and early appendicitisDiagnostic index of real acute inflammation. Ann Diagn Pathol. 2002;6(6)352-356.

doi:

[Article:https://doi.org/10.1053/adpa.2002.36659]

[Crossref]

03. Pieper $R$, Kager $L$, Näsman P. Clinical significance of mucosal inflammation of the vermiform appendix. Ann Surg. $1983 ; 197(3) 368-374$.

doi:

[Article:https://dx.doi.org/10.1097\%2F00000658198303000-00019][Crossref]

04. Tally NJ, Shroter RG, Philips SF, Zinsmeister AR. Eosinophilic gastroenteritis- a clinicopathological study of patients with disease of the mucosa, muscle layer and the subserosal tissue. Gut. 1990:31(1)54-58.

doi: [Article:https://doi.org/10.1136/gut.31.1.54] [Crossref]

05. Stemmerman GN. Eosinophilic granuloma of the appendix- a study of its relation to Strongyloides infestation. Am J Clin Pathol. $1961 ; 36 ; 524-531$.

doi: [Article:https://doi.org/10.1093/ajcp/36.6.524] [Crossref]

06. Stephenson J, Snoddy WT. Appendiceal lesionsObservation in 4000 appendectomies. Arch Surg. 1961;83(5)661-666.

doi:

[Article:https://doi.org/10.1001/archsurg.1961.0130 0170017005][Crossref]

07. Aravindan KP, Vijayaraghavan D, Manipadam MT. Acute eosinophilic appendicitis and the significance of eosinophil-Edema lesion. Indian J Pathol Microbiol. 2010;53(2)258-261.

doi: [Article:https://doi.org/10.4103/03774929.64343][Crossref] 
08. Carr NJ. The pathology of acute appendicitis. Ann Diag Pathol. 2000;4(1)46-58.

doi: [Article:https://doi.org/10.1016/s10929134(00)90011-x][Crossref]

09. Gaurav Jain, Sujata R Kanetkar. Eosinophilic appendicitis- Case report of five cases \& review of literature. J Med Res Pract. 2013;2(8)208211.

[Crossref]

10. Shivraj N Kanthikar, Dhiraj B Nikumbh, Sneha S. Desale- Primary Eosinophilic Obliterative Appendicitis. Online J Health All Sci. $2014 ; 13(1) 6$.

[Crossref]

11. Sinha RT, Dey A. A retrospective study of histopathological features of appendectomy specimens-what all can expect. J Med Sci Health. 2016;2(2)6-12.[

Crossref]

12. Norman J, Leslie H. Appendix, In- Weidner N, Cote R, Suster S, Weiss LM, Modern surgical pathology. 2nd ed, Saunders Elsevier. 2009 vol$1 \mathrm{pp} ; 837-852$.

[Crossref]

13. Rothenberg ME. Eosinophilic gastrointestinal disorders EGID). J Allergy Clin Immunol. 2004;113(1)11-28.

doi:[Article:https://doi.org/10.1016/j.jaci. 2003.

10.047][Crossref]

14. Alvarado A. A practical score for the early diagnosis of acute appendicitis. Ann Emerg Med. 1986;15(5)557-564.

doi: [Article:https://doi.org/10.1016/s01960644(86)80993-3][Crossref]
15. Bickell NA, Aufses Jr AH, Rojas M, Bodian C. How time affects the risk of rupture in appendicitis. J Am Coll Surg. 2006;202(3)401406.

doi:

[Article:https://doi.org/10.1016/j.jamcollsurg.2005.1 1.016][Crossref]

16. Polat DA, Münevver $M$, Selçuk $U$, MahirM $O$, VasfiM O, Selda S, Faruk C. Unusual findings in appendectomy specimens- Evaluation of 2458 cases and review of the literature. Indian Journal of Surgery. 2004;66(4)221-226.

[Crossref]

17. Blackshaw AJ, Levison DA. Eosinophilic infiltrates of the gastrointestinal tract. J Clin Pathol. 1986;39(1)1-7.

doi:

[Article:https://dx.doi.org/10.1136\%2Fjcp.39.1.1]

[Crossref]

18. Shrestha R, Ranabhat SR, Tiwari M. Histopathologic analysis of appendectomy specimens. J Pathol Nepal. 2012;2(3)215-219.

doi: [Article:https://doi.org/10.3126/jpn.v2i3.6025] [Crossref]

19. Bhangu A, Søreide K, Di Saverio S, Assarsson $\mathrm{JH}$, Drake FT. Acute appendicitis- modern understanding of pathogenesis, diagnosis, and management. The Lancet. 2015;386(10000)1278-1287. doi:[Article:https://doi.org/10.1016/S0140-6736(15) 00275-5][Crossref] 